\title{
Frustration grows over EU grant application procedures
}

Munich

Applying for research grants is always a complicated and time-consuming process. But many scientists across Europe are currently reserving their strongest complaints for applications to the European Union's (EU's) five-year Framework programme (FP5).

Not only are its application procedures especially cumbersome, claim researchers, but some say the chances of winning a grant are too low to justify the effort. Privately, some officials in the European Commission, which administers the programme, fear that the best researchers will be driven away.

Data emerging from the commission indicate that, after two rounds of proposals submitted last year, the success rate for applicants in the life sciences and information technologies - subjects earmarked by the EU as strategic priorities — remains below 20 per cent. In biotechnology, covered by a subprogramme called the 'Cell Factory', the success rate is as low as 10 per cent (see graph).

A Framework grant application involves recruiting a network of collaborating labs with an acceptable geographic balance: the chances of success are greater when researchers from smaller EU nations and from southern Europe are included. But FP5's requirement for projects to be justified in addition by their socio-economic value seems to be causing particular problems.

This requirement was agreed in 1998 by research ministers from the EU's member states and the European Parliament. Governments wanted FP5 to support research that directly addresses defined socio-economic

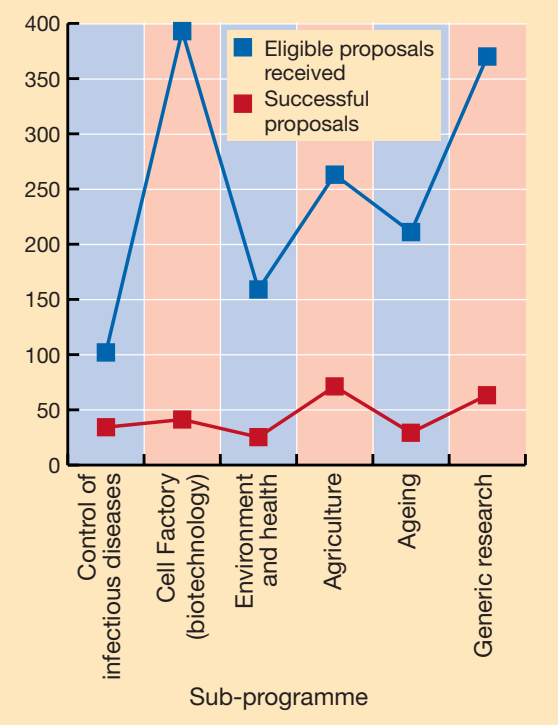

Slim pickings: EU grants require reams of paperwork, but the chance of success is small. problems in European states, rather than simply supporting basic research, which, according to the EU's governing treaties, is the job of individual member states.

Scientists are struggling to put the idea into practice, however, and commission officials admit that the new criteria are difficult to explain, except by example. "You find yourself having to read through hundreds of pages of advice in order to construct an application," complains one frustrated, although successful, FP5 applicant.

Given the low success rates, many scientists are questioning the value of the time and effort spent on putting together an application. "For an application coordinator, an FP5 grant application is an extremely difficult and time-consuming affair that can take up to six months," says Hans-Georg Rammensee, a cell biologist at the University of Tübingen in Germany. "A rejection rate of some 90 per cent in my area makes this effort a huge waste of resources." Rammensee, although a partner in three Framework projects, says he would never volunteer to coordinate an application himself.

"You have to be desperate to apply for EU money," agrees Paula Ricciardi-Castagnoli, an immunologist at the University of Milan who has experienced the system as both a successful and an unsuccessful applicant and as a grant reviewer. "Scientists from countries with better funding opportunities like Germany and Britain will obviously turn to their national funding agencies where application procedures are less cumbersome."

A possible way around this problem would be to divert more FP5 money into life sciences and information technologies, in order to raise the success rate to the desired target of 30 to 40 per cent. But the EU's finance rules mean that, until FP5 expires at the end of 2002, money cannot be shifted from less popular research areas.

Instead, the commission is trying to tweak the system by cutting the number, and narrowing the scope, of future calls for proposals. It is also considering ways of making the application process more user-friendly.

Bruno Hansen, director of life sciences for FP5, says that simplification is a "high priority". But he defends the socio-economic criteria, arguing that this will guarantee that the European population gains maximum benefit from EU-funded research.

"I am very optimistic that it will prove fruitful, particularly in areas such as food safety or the development of new vaccines," says Hansen. "However, it is too early to say whether it is actually working." Alison Abbott \& Patrick Weydt

๙ $\odot 2000$ Macmillan Magazines Ltd

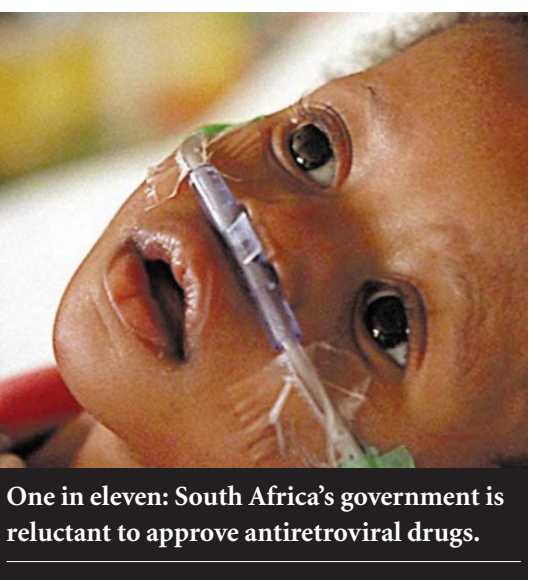

Deaths bring South African HIV drug trials to a premature halt

\section{Cape Town}

South Africa's Medicines Control Council (MCC) has halted a clinical trial of the antiretroviral drug Coviracil (emtricitabine) following an announcement by the country's health minister that five South African women have died during the trial.

The decision has attracted particular attention because the study involved giving Coviracil to HIV-positive individuals in combination with $\mathrm{d} 4 \mathrm{~T}$ and nevirapine.

The government is already under pressure to allow HIV-positive pregnant women to be given nevirapine to prevent mother-to-child transmission of HIV, since President Thabo Mbeki has refused to sanction the use of AZT in state hospitals for this purpose (see Nature 402, 332 ; 1999).

Health minister Manto TshabalalaMsimang has been accused of using the deaths to justify the government's refusal to provide pregnant women with antiretroviral drugs. "It is unfortunate that she has used the tragic event of deaths during the trials to make a political point that justifies her doing nothing to stop mother-to-child transmission," said opposition Member of Parliament Patricia de Lille of the PanAfrican Congress.

But Tshabalala-Msimang told parliament last week that it would be "immoral and unethical" for the government to decide on the use of nevirapine until the full results of clinical trials on the drug are available.

MCC head Helen Rees denied that the government had put pressure on the council in making its decision. She described the timing of events as "serendipitous".

Michael Cherry 